\title{
Caterina Albert y Grazia Deledda: Aproximación al tema de la mujer en su novelística
}

\author{
Elisa ARTEAga IRIARTE
}

I. Desde este breve artículo pretendemos acercarnos a dos autoras que se incorporan al mundo de las Letras en un momento en el que aún no era general el acceso de la mujer a estos círculos. A pesar de las dificultades que encuentran las escritoras en esta época, la nómina comienza a ser importante. Entre todas las narradoras que podríamos haber elegido, hemos decidido centrarnos en Caterina Albert y Grazia Deledda. Existen muchos puntos en común entre ellas, así lo vio F. Gelormini, traductor al italiano de la obra de Caterina Albert, quien responde a la escritora, agradeciéndole el envío de Caires vius en una carta fechada el 18 de junio de 1907, llena de elogios para la novela Solitud, que compara con las novelas de Grazia Deledda, carta cedida gentilmente por D. Lluís Albert, depositario de los fondos de la escritora catalana en L'Escala (Girona): "Le sentiment exquise, fine de votre roman Solitut n'a rien à envier en son genre, aux tants aplaudits romans de notre Grazia Deledda d'aujourd'hui."

Las coincidencias comienzan por la proximidad cronológica: Albert nace en 1869 y Deledda en 1871, ambas cara al Mediterráneo: la escritora catalana en L'Escala, alto Ampurdán, y la italiana en la isla de Cerdeña. Ambiente privilegiado el de Caterina, no sólo por tratarse de una familia acomodada, sino aperturista y muy aficionada a la lectura, hecho que facilitó su formación como escritora, incluso como pintora. Mayor fue la resistencia que hubo de vencer Grazia que había venido al mundo en un ambiente excesivamente tradicional, en el que no se consideraba admisible que una mujer se convirtiera en escritora, pese a lo cual en 1888-89 publica Paradiso dei bambini, Sulla montagna y Cose infantili, si bien su verdadera entrada en el mundo de las Letras tiene lugar con la publicación de Fior di Sardegna en 1892.

Coincidiendo con el comienzo de siglo, Albert publica un libro de poesías, El cant dels mesos, con el seudónimo Víctor Català, quizás para evitar reticencias por la incursión de una mujer en la Literatura, tal y como lo había comprobado por la presentación del monólogo L'infanticida a unos Juegos Flora- 
les en 1898 con su verdadero nombre. En 1902 publica Drames rurals y en 1905 su obra maestra Solitud, con la que obtiene el Premio Fastenrath en 1909. La desaparición de la revista Joventut en la que había publicado la mayor parte de sus relatos, pudo ser la causa, en parte, al menos, de un silencio literario que llega hasta 1917, cuando reaparece para presidir los Juegos Florales de Barcelona y publicar la novela 3.000 metres, reeditada en 1919 con el título Un film. En esta novela, el ambiente rural de sus primeras narraciones cede paso al de los bajos fondos barceloneses que, según la crítica, no logra plasmar con la misma autenticidad que consigue con el medio rural. En Barcelona tuvo el honor de ser nombrada miembro de la Real Academia de las Buenas Letras en 1923. Su vocación literaria no se apagará con los años. Si bien atravesó periodos de aridez, a los ochenta años publica Vida mòlta (1949). Albert murió en su pueblo natal en 1966. No fue tan dilatada la vida de la Deledda, quien moría en Roma en 1936. Como en el caso de Albert, escribió hasta el fin de sus días. En su novela La chiesa della solitudine, en parte autobiográfica, cuenta el episodio de su última enfermedad. En 1926 había recibido el Premio Nobel de Literatura, barajándose su candidatura frente a los nombres de D'Annunzio y Luigi Pirandello.

La obra de ambas autoras se desarrolla en un momento en que los cambios estéticos en literatura se suceden y superponen, participando nuestras autoras en mayor o menor medida de los mismos. Si bien, el eclecticismo de Caterina Albert la hace difícil de encuadrar en un movimiento concreto, nos basamos en la opinión de la crítica para comprobar de qué modo las tendencias de la época se reflejan en esta obra. La autora catalana escribe su obra en un periodo en el que decadentismo y simbolismo se encuentran en pleno apogeo, pero entre cuyas estéticas encontró también un lugar ferviente el componente naturalista. El mejor ejemplo sería Solitud para comprobar en qué modo se conjugan modernismo y naturalismo. A. Centellas Rodrigo (1993: 135-149) precisa el significado que toma en esta autora el naturalismo: a diferencia del naturalismo francés, marcado por el determinismo fatalista, ese aspecto no es del todo contemplado por el ruralismo modernista, con el que es afín la escritora catalana. No obstante, M. Montoliu (1972:LVI) resalta el pesimismo y fatalismo que encierra la visión que ofrece del ser humano, lo que puede ser tomado como influjo naturalista. El naturalismo se muestra también en algunas escenas entre las que destaca el capítulo $\mathrm{V}$ de Solitud, en el que se describe una popular caracolada y del que dice M. de Montoliu: “...l'autor hi desplega, un scherzo realista molt del gust d'un període en el qual perdurava entre els escriptors catalans l'admiració de certs canons estètics del naturalisme" (1972:LVI). Podemos añadir que la Albert se acerca en ocasiones a Zola por la valentía con que aborda ciertos temas. Volviendo al ruralismo modernista, refiriéndonos al modo de incorporar ese espacio a la estética modernista, dice M.R. Font (1993:205): "Víctor Català incorpora en las seves obres l'escenari rural com a espai simbòlic per a estudiar el desenvolupament d'un individu sotmès a les lleis obscures del medi i de la mateixa vida humana en la qual s'inspira". Ese es el tipo de espacio simbólico que sirve de escenario a Solitud. Paradójicamente, en plena época modernista, el ruralismo se convierte en moda, hecho 
que está ligado a la expresión de catalanismo que considera la campiña como germen de nacionalidad. Cuando Víctor Català publica Drames rurals en 1902, en fecha inmediata a Els sots feréstecs (1901) de Raimon Casellas, provoca confusión tanto en la literatura modernista como en el ruralismo de corte ochocentista. Algunos críticos hablan de "ampurdanismo" para referirse a una visión estereotipada del mundo rural en Caterina Albert. La estética modernista es capaz de combinar esos temas con otros propios como el "demonismo" o triunfo del mal. Víctor Català escribió hasta bien mediado el siglo XX, pero su obra queda marcada por las corrientes de principios de siglo. Solitud puede considerarse compendio de todas ellas: últimos ecos del romanticismo, costumbrismo, naturalismo, modernismo, impresionismo. Así lo reconoce B. Porcel (1986:VII).

En el caso de Grazia Deledda, también pueden rastrearse huellas del romanticismo en su primera novela Sangue sardo (1888). Sintió gran admiración por Victor Hugo, pero su romanticismo está más cerca del escritor ruso Turgueniev. La semejanza entre los dos autores ha sido analizada por M. ${ }^{\mathrm{a}} \mathrm{L}$. Dodero Costa (1986). Del romanticismo deriva el costumbrismo de sus primeras narraciones, especialmente los frescos de la vida rural sarda, comparables por su lirismo con el escritor inglés Thomas Hardy. El costumbrismo servirá de trampolín hacia el realismo, que en Italia tomará el nombre de "verismo" y cuenta en ese país con una figura universal como Giovanni Verga. Según E. Pilia (1926:137), la Deledda pasó del costumbrismo romántico de las primeras narraciones a la novela regionalista siguiendo la línea de G. Verga. Su crítico M. Micinesi (1975:77-78) concede mayor importancia al influjo ejercido por el medio, que al deseo de la escritora por incorporarse a las corrientes regionalistas. A medida que evoluciona su estilo disminuyen los elementos costumbristas y folklóricos para ceder paso a componentes propios de la novela realista: descripción de espacios, ahondamiento en la psicología de los personajes, comportamientos individuales en choque con la sociedad. El realismo se hace patente en sus mejores novelas de principio de siglo: Elias Portolu (1900), Cenere (1903), Canne al vento (1913). Si bien la contemplación del naturalismo intensifica los rasgos realistas, ninguna novela en su conjunto puede tomarse como estrictamente naturalista. La escritora italiana rechaza el determinismo científico impuesto por Zola. El naturalismo deleddiano apenas se muestra en alguna alusión científica incluida en la narración como ocurre con la explicación de ciertos fenómenos histéricos en Il Dio dei viventi (1922). El simbolismo incide en la obra deleddiana a partir de Marianna Sirca (1915). La autora sarda siente la necesidad de superar los límites realistas y para ello incorpora a su narrativa el componente simbólico. Como en el caso de los nexos naturalistas, acoge con cautela ciertos presupuestos simbolistas, distanciándose de D'Annunzio al no admitir el decadentismo sensual del gran escritor simbolista italiano. Para De Michelis (1938:62) las novelas publicadas en el periodo comprendido entre 1918-1924 son plenamente simbolistas. El simbolismo llega al cénit en algunos títulos como Il segreto dell' uomo solitario (1921) e Il paese del vento (1931). En sus últimas narraciones, Grazia Deledda se centra en la novela psicológica, vuelve a fuentes biográficas y autoanalíticas como res- 
puesta a sus inquietudes personales y también al influjo de la corriente decadentista. Nos inclinamos a creer que la narrativa de Grazia Deledda recibe el influjo de las corrientes literarias de su tiempo, pero como en el caso de Víctor Català toma de ellas aquellos rasgos con los que se identifica su propia concepción ética y estética.

Sobre la base de ese telón de fondo y dejando al margen la posibilidad del conocimiento mutuo de su producción - lo cual parece improbable tras el rastreo que hemos realizado de la divulgación de sus obras, respectivamente de Deledda en España y de Albert en Italia-, creemos que es oportuna la aproximación comparada a ambas autoras. Más aún cuando en sus obras hay otros tantos nexos argumentales, por ejemplo, el de los paisajes de gran parte de su existencia, L'Escala y Nuoro, que nutrieron de tradiciones y tipos campesinos parte de su imaginario. La presencia de la mujer como eje argumental de buena parte de sus textos, es otro punto de encuentro entre sendas novelistas. Cuestión esta última que se asienta sobre la condición de mujer-escritora de Albert y Deledda, nos parece más que suficiente justificante para esta incursión comparatista.

II. El hecho de que, como hemos apuntado anteriormente, la mujer ocupe un lugar destacado en la narrativa de estas autoras, proporciona al discurso un tono marcadamente feminista, del que no es ajeno el influjo que ejerció en la literatura decimonónica el estreno en 1879 de Casa de muñecas del célebre dramaturgo noruego Henrik Ibsen. Podríamos incluso considerar que en el desenlace de Solitud hay un paralelismo con la decisión de Nora, protagonista del citado drama, pues ambas heroínas eligen el camino de la soledad para encontrarse a sí mismas.

El individualismo del que siempre hizo gala Caterina Albert no le permitió comprometerse con movimientos feministas radicales. Recuerda N. Nardi (1993:332) el discurso que pronunciara con motivo de la inauguración de los Juegos Florales de 1917, en el que quedó claramente expuesta su posición frente al feminismo. La idea que destaca la mencionada estudiosa en dicha ocasión es la de que la reivindicación de los derechos de la mujer no puede aislarse del proceso educativo de la sociedad. Una sociedad en la que, sin duda, tuvo que librar la Albert dura batalla para que la aceptaran como escritora y para no arredrarse ante el escándalo que produjo el hecho de que abordara con crudeza ciertos temas que levantaron polvareda en la opinión pública, empeñada en relacionar vida y obra.

$\mathrm{Al}$ situar la acción de sus narraciones, preferentemente, en el mundo rural tiene ocasión de denunciar la marginación de la mujer en este medio y la pasividad con que se vivían situaciones degradantes, sin un gesto de rebelión, aunque en los rostros de tantos personajes femeninos haya quedado impreso el dolor, como Doloretes, en el relato de Drames rurals, Daltabaix: "Als dotze mesos de casada, la pobra Doloretes, com li diuen els veïns, seca mateix que un lluquet, amb la cara xuclada i descolorida, ulls místics, la boca closa amb un gest dolorit i el cabell fosc i ros limbant-la lacònica i resignada" (1972: 
480). Podríamos citar tantos ejemplos, pero para cualquier referencia es imprescindible volver a Mila, personaje estelar de Solitud y de toda su producción, que resume la personalidad femenina. Una especie de Eva en el Paraíso, liberada de la culpa de hacer caer al hombre. Reléase el pasaje bíblico revivido en la ermita del Cimalt por los tres personajes protagonistas: Mila (Eva), Maties (Adán) y la tentación encarnada en el Ânima, quien tienta a Maties y violenta a Mila, pero no la doblega, aunque sí consigue que se produzca la ruptura entre hombre y mujer, que en adelante caminarán separados. Para Mila va a ser el comienzo de un proceso de evolución hacia el encuentro consigo misma. Las mujeres descritas por Caterina Albert, en esta línea, están muy lejos de parecerse a las heroínas idealizadas de la novela modernista de corte pre-rafaelista o d'annunziano. Por el contrario, surgen de la realidad histórica con la acuciante necesidad de buscar su propia identidad.

También Grazia Deledda se mantuvo alejada de los ambientes feministas, que en la Italia de la época tuvo como credo Una donna, novela autobiográfica de Sibilla Aleramo, publicada en 1906. No precisó Deledda, sin embargo, de modelos literarios del movimiento feminista para crear situaciones y personajes que parecen surgidos de esta ideología, ya que en su propio medio encontró abundantes motivos para alzar la voz en defensa de los derechos de la mujer a ingresar en el mundo de la cultura y a buscar su propio destino sin necesidad de recurrir a un matrimonio convencional. Deledda pone el acento en las mismas cuestiones que la escritora catalana, aunque, en cierto modo, se muestre más conservadora y se centre especialmente en el problema de la educación. La mujer es también centro de su narrativa en la mayoría de los casos.

Habitualmente, podemos advertir que los escritores adoptan dos posiciones, o bien trazan en los personajes perfiles diametralmente opuestos a su propia personalidad o proyectan sobre los mismos rasgos propios. Pensamos que entre los personajes femeninos de Caterina Albert podemos encontrar escasas coincidencias con su creadora: hemos hablado, en términos generales, de seres sumisos, primitivos, a los que encontraremos realizando tareas caseras o trabajando en el campo, sin conciencia de sus necesidades o derechos, por lo que difícilmente pueden plantearse el problema de su formación. Albert pretende exponer la situación de tantas mujeres que no han tenido sus oportunidades porque han nacido en un medio social y cultural muy distante al suyo. Rescatará a Mila del destino al que están abocadas la mayor parte de sus heroínas porque en ellas vierte la autora cierta dosis del espíritu rebelde que la caracteriza y por la intervención de Gaietà, guía espiritual, que la ayuda a encontrar el camino. Por el contrario, Grazia Deledda adopta con frecuencia en sus narraciones el autobiografismo, son numerosas las heroínas en las que se advierte la proyección que la autora hace de sí misma, con constantes alusiones a la formación cultural coincidentes con su propia biografía. En uno de sus primeros relatos, I primi passi, incluido en La vigna sul mare, nos pone al corriente de oposiciones y anécdotas que jalonan su entrada en el mundo literario; en $I l$ paese del vento se reflejan episodios sentimentales e impresiones de recién casada; los temores a la enfermedad y la 
muerte son experiencias expuestas en La chiesa della solitudine. Pero la novela considerada declaradamente autobiográfica es Cosima. Posiblemente, por tratarse de una cuestión que la afectó directamente, aunque sea de manera velada, se cuestionan constantemente las tradicionales costumbres que excluyen a la mujer del mundo de la cultura y la obligan a cultivarse de forma autodidacta por medio de lecturas, elegidas arbitrariamente. Así la lectura de novelas que se considera pecaminosa y debe ocultarse, posiblemente porque se considera puede abrir puertas hacia la libertad personal. Tomamos estas líneas de Cosima como ejemplo: "Anche leggendo già di nascosto i libri del fratello maggiore, e quelli che esistevano in casa, pensava a una vita lontana, diversa dalla sua" (1981: 33). La proyección personal sobre los personajes femeninos dota a éstos de una complejidad y riqueza de matices, que los hace muy humanos. Si bien, en ocasiones, cae en cierto maniqueísmo. Así podemos encontrar en Cenere la abnegación de Olì, generosa hasta la inmolación frente a la postura egoísta y fría de Margherita. También en Colombi e sparvieri se da el antagonismo de dos mujeres, que inciden sobre el protagonista Jorgy: la benéfica ayuda de María y la actitud pusilánime y mezquina de Colomba. La negatividad de algunos de estos personajes no nos parece, sin embargo, tener otra intención que resaltar la virtud de su oponente. En términos generales, las mujeres de la narrativa deleddiana se caracterizan por ser sentimentales, con un carácter inquebrantable y una apasionada sensualidad. Tampoco, como sucede con Caterina Albert, encontramos la mujer ninfa, característica de la novela de principios de siglo esteticista al modo d'annunziano.

Otro aspecto que nos parece interesante considerar es el tema amoroso como primordial componente de la narrativa que analizamos. Diremos en primer lugar que las historias sentimentales revisten características propias del medio en que se desarrollan y del influjo de las tendencias de la época: así en El carcanyol, de la colección de relatos Caires vius, Caterina Albert se adhiere al tono tremendista de la novela folletinesca, que tuvo abundante expresión en la literatura de principios de siglo. Este relato se centra en la caída de una familia noble iniciada con entrada en la misma de un personaje siniestro, Jo,o Carvalho. El tema de la infidelidad matrimonial aparece en El calvari d'en Mitus, otro relato recogido en Caires vius, consecuencia de un matrimonio de interés sobre el que se impone la fuerza de la pasión. Los matrimonios convencionales impiden, no pocas veces, que el verdadero amor se frustre, como se cuenta en el relato de Ombrívoles, Almes mudes, en el que el abuelo Peró y la abuela Xuriguera, a pesar del amor que se han profesado durante toda la vida, se van de este mundo sin haber podido dirigirse una palabra afectuosa. El amor que profesa Mila por Gaietà, los personajes de Solitud, es un amor elevado, como lo es el espacio simbólico en el que se desarrolla la historia. Con "el pastor" podría haber encontrado Mila su pareja ideal, eran muchas las afinidades entre ellos, sin embargo, la diferencia de edad y la fidelidad de Gaietà al recuerdo de su esposa, impiden cualquier relación que no tenga carácter espiritual. Por otra parte, la intención de la autora es abandonar a Mila a la soledad, como medio de auto-conocimiento. 
El amor en la narrativa deleddiana tiene un papel estelar. Muchas de estas historias sentimentales se viven en la clandestinidad, porque trasgreden las normas sociales, bien por adulteras o incestuosas. Un ejemplo lo encontramos en Elias Portolu, quien busca en el sacerdocio el alejamiento de su cuñada. Compartimos la opinión de O. Lombardi cuando afirma: "L'amore è raramente un sentimento puro nella narrativa deleddiana" (1989:96). Con frecuencia el sentimiento nace espontáneo y tiene como marco la naturaleza y, como en la historia entre Mila y Gaietà, el medio natural aporta al amor una dimensión trascendente. Observamos que ni el amor estrictamente carnal, ni el trato vejatorio de la mujer, que podemos encontrar en la narrativa de Caterina Albert, son elementos que se den en la obra de la escritora italiana.

Por el contrario, coinciden nuestras autoras en separar amor y matrimonio. Si en Caterina Albert descubrimos un claro escepticismo ante el amor, éste se acrecienta en el caso del matrimonio. Su visión negativa aparece en muchas narraciones, podríamos decir que es la tónica general. Si exceptuamos algunos ejemplos, veremos que la feliz convivencia del matrimonio protagonista de L'enveja, relato de Drames rurals, no tiene otra preocupación que la de ser padres. También sabemos que Gaietà fue feliz con su esposa, aunque el matrimonio acabara tristemente con la prematura muerte de ella. También de la narrativa de Grazia Deledda podemos extraer numerosos ejemplos que muestran una visión negativa del matrimonio. En Nostalgie, leemos: "Una donna superiore non si sposa mai; o se si sposa, durante un periodo d'inconscienza, se ne pente presto" (1969:219). De la lectura de estas narraciones se deduce que no culpabiliza del fracaso al hombre ni a la mujer, sino a la sociedad que impone el matrimonio interesado, no elegido por los contrayentes. Un matrimonio ventajoso al que están destinadas tantas heroínas, cuyo ejemplo paradigmático es el de las hermanas Pintor, protagonistas de Canne al vento, quienes viven bajo la tiránica tutela del padre que las mantenía: "...chiuse dentro casa come schiave le quattro ragazze in attesa di mariti degni di loro" (1957:384).

No pueden abordarse ciertos aspectos de la condición femenina sin aludir a las menciones que encontramos en ambas autoras sobre la maternidad. En contra de lo que suele suceder con otras escritoras, encontramos en estas narraciones, tanto de la escritora catalana como en el caso de la italiana, escasez de personajes infantiles; sin embargo, no puede negarse que el sentimiento maternal late en tantas heroínas que pueblan las páginas de la obra de estas escritoras, aunque, como en el caso de Mila, sea un deseo no cumplido, sublimado por la ternura que siente por Baldiret, el monaguillo de la ermita del Cimalt. Grazia Deledda da el nombre de La madre a una de sus más conocidas novelas, en la que centra la acción sobre esta figura que vela por el hijo sacerdote, pero es en Cenere donde realmente Deledda entona un canto a la abnegación materna en la figura de Olì, ejemplo patético como lo son algunas historias de Caterina Albert entre las que destaca el dramatismo de Nela, protagonista de L'infanticida, en el que la escritora expone el caso extremo de una mujer soltera que, incapaz de enfrentarse al hecho de haber dado a luz una hija en la casa paterna $\mathrm{y}$, ante el temor de ser descubierta, pasa a la recién nacida por una rueda de 
molino. Creemos que tanto Cenere como L'infanticida son una clara denuncia de la sociedad de la época que empuja a la madre soltera a soluciones dramáticas. M. Ll. Julià resalta el hecho de que en la narrativa de Caterina Albert:" Quan les relacions són fruit de l'amor, la dona concep un filla, una nena(...). En canvi, quan la maternitat és consequiència de la convenció matrimonial, de la seducció o del simple acoblament, el fruit d'aquestes relacions sempre és un fill mascle" (1993:261). Nos preguntamos si la autora ha querido insistir de este modo en el hecho de que ni siquiera la relación madre-hijo puede salvar la distancia que existe entre el hombre y la mujer. La diferencia para Grazia Deledda no estriba en la diferencia de sexo, sino en que los hijos hayan nacido del amor, así leemos en Il rifugio, relato de La vigna sul mare: "I suoi figliuoli, maschi o femmine che siano saranno tutti felici, se la loro madre vivirà solamente per loro. Ma è di questo che ho paura. Io non potrò vivere per loro; io non li amerò perche i figli che non nascono dell'amore non possono essere amati" (1955:667).

Las complicadas relaciones que se establecen entre hombres y mujeres en las narrativas que comentamos son facilitadas por unos personajes, que sirven de puente, especie de guías o consejeros, generalmente ancianos en contacto con la naturaleza y que, una vez superadas las necesidades materiales, viven en un plano espiritual, por lo que pudieran parecer asexuados. El franciscanismo de estas figuras es una muestra de la incorporación del Santo de Asís a la literatura realista. V. González Martínez (1982) ha analizado la relevancia de los guías espirituales en la obra de E. Pardo Bazán, que podríamos extender a la narrativa de otros autores. Podríamos añadir que, tanto en Caterina Albert como en Grazia Deledda, al modelo de los eremitas o guías se añade el influjo del modernismo, en cuanto al interés por las experiencias espiritualistas, en las que se mezclan ideas teosóficas y panteísmo, teorías rescatadas por el movimiento finisecular y mediante las que se formula ese modelo de personajes. En la novela de Caterina Albert es emblemática la personalidad de Gaietà, el pastor nimbado de atributos extraordinarios, que sabe dar buenos consejos y contar hermosas leyendas a Mila. Es innegable que a través de la comunicación que se establece entre ellos, la mujer encuentra el verdadero camino. Los ancianos cumplen por su parte, en la obra deleddiana, la misión de conservar la ecuanimidad y recto juicio, suplen en ciertos casos a la figura paterna. De ellos dice $O$. Lombardi: "...quasi sacerdoti di una religione della famiglia, custodi dell' onore di questa..." (1989:95). Es ese el papel que cumple Efix en Canne al vento, pues en cierto modo suplanta al padre de las hermanas Pintor, sustituyendo autoritarismo por entrega generosa.

Además de plasmarse la visión femenina en temas trascendentes - amor, matrimonio, maternidad - - se advierte en otros aspectos, que podríamos considerar neutrales, como ocurre en la descripción del paisaje, en las que se transparenta cierta sensibilidad peculiar a la que se incorporan ciertas técnicas propias del momento. La plasticidad de las descripciones en la obra de Caterina Albert es una muestra de su faceta artística de pintora: pinturas realistas, en principio, como técnica empleada para dar a conocer las costumbres del medio rural, pasan a ser posteriormente, bajo el influjo naturalista, de descripción 
impresionista y en las que los personajes y el ambiente se impregnan de una sensualidad muy al gusto modernista. De la identificación entre paisaje y personaje hay numerosas muestras en Solitud, utilizadas sabiamente por la autora para mostrar la transformación de la personalidad de Mila, quien, en principio, adopta hacia el paisaje una actitud contemplativa; después comienza a sentir cómo ella misma forma parte de la naturaleza, para finalmente, lograr la integración armónica en el Cosmos: “...grans masses de formes vagues nedaven en una penombra bruna, plena de misteri; d'aquella penombra semblava brollar suaument, com les aromes del pebeter, aquell profund silenci, ple d'harmonies inoïbles, que ho invadia tot arreu..." (1990: 304). La misma trayectoria sigue Grazia Deledda para pintarnos el paisaje sardo y sus costumbres: bodegones realistas, centrados, de modo especial, en la típica cocina sarda, en la elaboración de platos regionales y conservación de confituras que descubren a la escritora en su doble papel de ama de casa. Se incorpora a las nuevas técnicas utilizando con maestría los cambios de distancia y perspectiva. Con frecuencia, son incisos que se confunden con el relato para subrayar, como en el caso de Caterina Albert, sensaciones o estados de ánimo. Uno de los mejores ejemplos lo encontramos en $I l$ paese del vento, identificando los cambios que experimenta la naturaleza con el paso de las estaciones y el ánimo de los personajes: "La primavera pareva si fosse di un tratto mutata in autunno; dell'autunno aveva il freddo verde dell'erbe, e il colore giallo-rosso dei fiori delle siepi, delle foglie di certi alberi, del cielo stesso..." ( 1959: 829). Se ha producido un cambio en la vida de los protagonistas subrayado por la metamorfosis de la naturaleza.

Hemos podido comprobar que existen numerosos puntos en común entre ambas autoras. Sin embargo, no tenemos noticia de que existiera conocimiento entre estas escritoras ni de que, al menos, hubiera un conocimiento mutuo de la obra. No obstante, Solitud fue traducida al italiano en 1918 por Alfredo Giannini Lanciano (G. Carabba editore), trece años después de su publicación en Barcelona. La relación entre Cataluña e Italia es significativa a la vista de la prontitud con que se traduce la novela de Caterina Albert. El mismo caso ocurre con la producción de Grazia Deledda, cuyas primeras publicaciones españolas se hacen en Barcelona: Miguel Domenge Mir traduce Cenere en 1906 (Ed. Henrich y Cia.) y La via del male en 1910, publicada en la misma editorial. La explicación de este interés, que en Cataluña despierta Deledda, pudiera formar parte de la tradicional relación entre Cataluña e Italia que, ciertamente y como indica J. Arce, había sido muy estrecha en lo que se refiere a contactos históricos con Cerdeña: "Questo si spiegherà forse con la vicinanza geografica o coi legami culturali e storici che uniscono la Sardegna alla Catalogna". (1971:73), También F. Meregalli se ha interesado por la resonancia que la obra de Deledda ha tenido en España, a la vista de la pronta traducción de sus primeras novelas y a la inclusión de sus más renombrados títulos en la colección dedicada a los Premios Nobel por la editorial Aguilar en una edición de 1955, a la que seguirá un segundo volumen publicado en 1958. Afirma el crítico: "Che io sappia in nessun'altra lingua si è tradotto tanto Grazia Deledda" (1992:333). Coincide F. Meregalli con J. Arce en atribuir este hecho a 
motivos históricos: "Certo vi è, al fondo, un interesse specifico degli spagnoli per la Sardegna, che ebbe per secoli rapporti stretti prima col regno d'Aragona, poi con la Spagna unificata." (1992:334).

El paso del tiempo es el mejor catalizador para juzgar una obra de arte, una vez que quedan atrás prejuicios y apasionamientos y, en la medida que es posible, la crítica se acerca a la imparcialidad. Los valores que podemos encontrar en tantos relatos y novelas de las autoras que estudiamos han sido refrendados en recientes congresos en los que han participado estudiosos, que han puesto de relieve distintos aspectos de la narrativa de Caterina Albert y Grazia Deledda. A la escritora catalana se han dedicado "Les Primeres Jornades d'Estudi sobre la vida i l'obra de Caterina Albert i Paradís 'Víctor Català"' en L'Escala, abril 1992. A la italiana "Il Convegno di Studi deleddiani", celebrado en Nuoro en 1986.

\section{EDICIÓN DE TEXTOS CITADOS}

\section{ALBERT, Caterina "Víctor Català":}

(1972): Obres Completes, segona edició, pròleg de M. Montoliu, epíleg de M. ${ }^{a}$ A. Capmany, Editorial Selecta, Barcelona.

(1990): Solitud, edició crítica de N. Nardi, Edicions 62, Barcelona.

DELEDDA, Grazia:

(1955): Il rifugio, relato de La vigna sul mare ( col. Romanzi e novelle, vol. IV, 1. ${ }^{\mathrm{a}}$ edic.), Mondadori, Milano .

(1957): Canne al vento (col.Romanzi e novelle, vol.I, 7. edic.), Mondadori, Milano.

(1959): Il paese del vento (col. Romanzi e novelle, vol. III, 3. ${ }^{a}$ edic.), Mondadori, Milano.

(1969): Nostalgie (col. Romanzi e novelle, vol. V, 1. ${ }^{\mathrm{a}}$ edic.), Mondadori, Milano. (1981): Cosima (4. a edic.), Mondadori, Milano.

\section{BIBLIOGRAFÍA CRÍTICA}

Sobre Caterina Albert:

Centellas Rodrigo, A. (1993): "Solitud de Víctor Català: un texto para una experimentación comparatista" (pp. 135-149)*.

FonT, M. ${ }^{\mathrm{a}}$ R. (1993): “Un film (3.000 m.): La resposta de Víctor Català als models noucentistes" (pp. 203-204)*. 
Julià, M. à Ll. (1993): “Les imatges de la dona en la narrativa de Víctor Català" (pp. 247-274)*.

NARDI, N. (1993): “ A propòsit d'Encunys” (pp. 321-352)*.

PORCEL, B. (1986): “Caterina Albert: Un retrato", introducción a Soledad, versión española de Basilio Losada, Alianza Edit., Madrid.

(*) Actes de les Primeres Jornades d'Estudi sobre la vida i l'obra de Caterina Albert i Paradís "Víctor Català". L'Escala, 9-11 d'abril del 1992, Publicacions de L'Abadia de Monserrat, 1993.

Sobre Grazia Deledda:

De Michelis, E.(1938): Grazia Deledda e il Decadentismo, La Nuova Italia, Firenze.

ARCE, J. (1971): "La Deledda en España”, Ichnusa, Sassari (nº 7).

Dodero CostA, M. ${ }^{a}$ L. (1992): "Grazia Deledda e Turgueniev" (pp. 277-283), Consorzio per la pubblica lettura S. Satta, Nuoro.

LOMBARDI, O. (1989): Invito alla lettura di Grazia Deledda, Mursia, Milano.

Meregalli, F. (1992): "Grazia Deledda in Spagna" (pp. 333-335), Consorzio per la pubblica lettura S. Satta, Nuoro.

Micinesi, M. (1975): Grazia Deledda, Il Castoro, Firenze.

PILIA, E. (1926): "Lettura narrativa in Sardegna”, Fondazione Il Nuraghe, Cagliari.

Otros textos:

Aleramo, S. (1991): Una donna, Feltrinelli, Milano.

González Martínez, V. (1982): "San Francisco de Asís en la Literatura Española", Verdad y Vida (núms. 157-158, 211-220). 